\title{
Time Series Long-Term Forecasting of per Capita Electricity Consumption for Bangladesh
}

\author{
Md. Hasan Ali', Robiul Islam Rubel ${ }^{2 *}$ and Md. Ariful Alam³ \\ ${ }^{1}$ Department of Industrial Engineering, Dalhousie University, Halifax, Nova Scotia, Canada \\ ${ }^{2}$ Department of Agriculture and Biosystem Engineering, South Dakota State University, SD, USA \\ ${ }^{3}$ Department of Industrial and Production Engineering, Bangladesh Army University of Science and Technology, Saidpur-
}

5310, Bangladesh

\begin{abstract}
Bangladesh government has announced Vision-2041 of electricity generation and distribution to uplift the socio-economic conditions of Bangladesh. It is now entering into the list of middle-income countries and now planning for energy as one key measure to sustainable development. Policymakers are trying to forecast the future per capita electricity consumption and set up a feasible way of electricity generation over longer periods for sustainable development of Bangladesh through preventing underestimation or overestimation that could cause a huge loss in the financial sector of Bangladesh. This work focuses on long-term estimation of electricity consumption for Bangladesh, time series models have been used to forecast per capita electricity consumption from fiscal year (FY) 2019/20-2040/41 (next 22 years). An actual past historical data of FY 1976/77-2018/19 (43 years) has been analysed on Minitab 17 to get the most favourable time series model for forecasting per capita electricity consumption of Bangladesh. ARIMA has appeared as the most accurate time series model over the actual historical data of 43 years with the lowest MAPE, MAD, and MSD as $4.50,3.23$, and 15.40 , respectively.
\end{abstract}

Keywords: forecasting; electricity consumption; sustainable development; time series models; ARIMA

\section{INTRODUCTION}

Bangladesh is one of the fastest developing countries reported by the Asian Development Bank (ADB) (Bangladesh and Asian Development Bank, 2018). Bangladesh has declared energy as a main sector of the Sustainable Development Goals (SDGs) (Sustainable Development Goals of Bangladesh, 2015), of the United Nations agreement to be achieved by the year 2030 (Sustainable Development Agenda in United Nations, 2015), and planned to reach high-income country status through Vision 2041 (Bangladesh Development Update, 2019). Among the SDGs of Bangladesh, self-dependency in the energy sector is the leading one. With the rapid industrialisation and development, electricity consumption in Bangladesh has drastically increased over the last two decades (Key Energy
Statistics of Bangladesh, 2018). Considering Bangladesh's current economic growth and improved quality of living standards (World Bank Data, 2018), self-dependency and self-sustainability in electricity are essential. Therefore, good planning of electricity generation and estimation of future per capita consumption is essential to secure the SDGs.

According to the International Energy Agency (IEA), developing regions such as countries from Asia and Africa are anticipated to experience a high need for energy from the year 2017 to 2040 (World Energy Outlook, 2018). Being a developing country, the growing economy of Bangladesh needs uninterrupted electricity in the near future.

Bangladesh Power Development Board (BPDB) has reported $374.62 \mathrm{kWh} /$ per capita electricity consumption in FY 2018/19, which is pretty high compared to its first 
estimated quantity in FY 1976/77 (Bangladesh Power Development Board, 2019). An overall jumped of $96.69 \%$ is noticeable for the passage of FY 1976/77-2018/19 (43 years), where the source for the electricity comes from different energy sources as presented in Figure 1 (Bangladesh Power Development Board, 2019). This increasing rate would probably continue and will be accelerated due to the government policy to obtain SDGs (Sustainable Goals Tracker, 2018). To comply and support this development process, proper prediction of electricity consumption up to the year 2041 (Vision-2041) is essential to guide the proper use of resources shown in Figure 1 and reduce financial losses that may occur due to lack of proper statistical data analysis of the past consumption. Historical demand data or consumption per capita data can be a good tool, which can be arranged in a time-series manner to predict the future electricity consumption per capita in Bangladesh up to 2041.

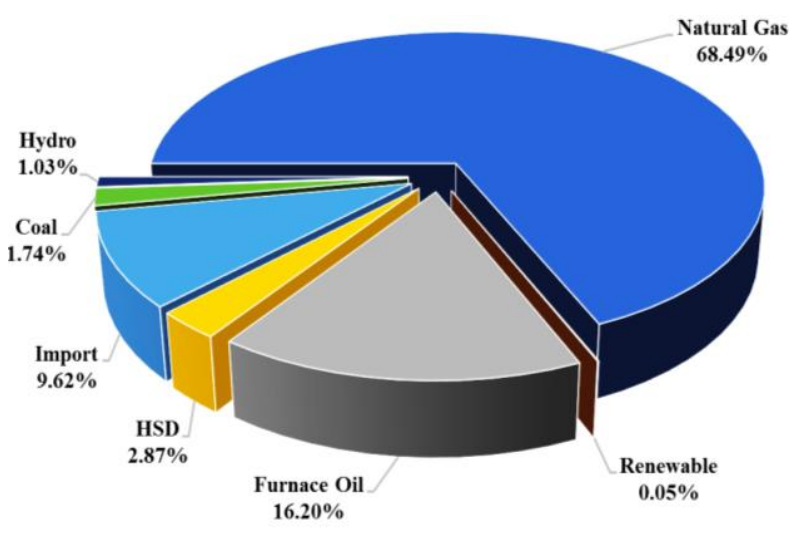

Figure 1. Electricity production scenario of Bangladesh FY 2018/19

(Source: Bangladesh Power Development Board, 2019)

Time series analysis is a widespread technique for demand forecasting (Gooijer \& Hyndman, 2006), with smoothing techniques (Maçairaa et al., 2015), trend analysis (Zahan \& Kenett, 2013), decomposition and statistical analysis (Wang et al., 2012), regression-based techniques (Rahman et al., 2018) has been used in the energy as well as electricity forecasting (Tepedino et al., 2014). The major aspect of forecasting with the time series model is to identify the various energy consumption trends (Campillo et al., 2012), which will lead to policy adaptation regarding demand response. For example, Stoimenova et al. (2007), Lee et al. (2018), Jain et al. (2018), and Ostertagova et al. (2012) has used time series model with different smoothing techniques to determine and forecast future energy as well as electricity consumption for different sector and community. The statistical period (Hussain et. al., 2016; Lepojevic \& Andelkovic-Pesic, 2011) and smoothing techniques (Ostertagová \& Ostertag, 2012; Lepojevic \& Andelkovic-Pesic, 2011; Oliveira \& Oliveira, 2018) of the actual data were different depending on the real situation of the cases (Stoimenova et. al., 2007; Hussain et al., 2016), though time series forecasting (Razak et al., 2009) can significantly enhance the forecasting accuracy with a limited span of historical data (Jiang et al., 2020).

Researchers of different country (Sisman, 2016; Nawaz et al., 2014) and organisation (Sen et. al., 2016; Nepal et al., 2020) has used and relied on the times series for its accuracy in energy forecasting (Oliveira \& Oliveira, 2018; Sisman, 2016; Shilpa \& Sheshadri, 2017) as well as in other sectors (Sen et al., 2016). Oliveira et al. (2018) have rated time series forecasting as an improved method not only for developed countries but also for developing countries in case of longterm forecasting (Jain et. al., 2018; Chujai et al., 2013). Rajbhandari et al. (2021) studied the effect of temperature and weekends and weekdays in short-term electricity demand forecasting in the urban area of Nepal while using a time series model with Artificial Neural Networks (ANNs).

This study used the time series forecasting model as a benchmark and the ANNs model developed as feedforward to track the effect of temperature and weekends and weekdays. It was found that the time series model with ANNs performed better in terms of Mean Absolute \%age Error (MAPE) on a weekday by $0.34 \%$ and $8.04 \%$ on weekends. An Adaptive Neuro-Fuzzy Inference System (ANFIS) was used to predict time series electricity demand in Ghana (Acakpovi et al., 2020). Data from 2003-2018 was collected and ANFIS was applied in MATLAB using various scenarios. Then the results were compared with SVR, Least Square Support Vector Machine (LS-SVM), and ARIMA and concluded that ANFIS performed prediction accurately with reliable data for training and reliable parameters setting.

Previously, the time series model (Tirkeş et. al., 2017; Towards Data Science, 2019) has been applied for electricity demand or consumption forecasting for Bangladesh. Few pieces of research emphasised local demand forecasting, few 
on short-run forecasting, and some for countrywide and longrun forecasting. It has been found that a local electricity demand forecasting for Rajshahi city in Bangladesh done by Sarkar et al. (2015) for the year 2012 to 2020 using Fuzzy Linear Regression model of time series. They used annual average temperature, annual consumer number, and annual electricity consumption data from the year 2001 to 2011. The lowest MAPE found was 1.24\% for the years 2012 and 2013. The same approach has been used for local energy forecasting of an isolated island (Kutubdia) in Bangladesh. They forecasted the 12-month electricity demand for the island (Kutubdia) using inverse matrix calculation and linear regression analysis (Islam et al., 2013). Since the island is isolated, no past data was found and therefore, the forecasting was done based on the identification of the key driving factors for the electrical load growth of that area rather than using the historical data.

Another local electricity demand forecasting for Chattogram City in Bangladesh was addressed by Islam et al. (2020). This study applied Long Short-Term Memory Network (LSTM) and results were compared with the Support Vector Machine (SVM) and LSTM outperforms SVM with the reduction of $52.24 \%$ and $\mathbf{2 1 . 6 7 \%}$ error in MAE and RMSE, respectively. For the short-run energy demand forecasting, several machine learning algorithms namely $\mathrm{K}$ Nearest Neighbor, Random Forest, and Long Short-Term Memory (LSTM) were applied for short-term (3 years) energy demand forecasting of Bangladesh (Mahmud et al., 2019). In particular, the time series investigation of the causal relationship between electricity consumption and real GDP for Bangladesh from the year 1971 to 2014 has done by Dey and Tareque (2019). They have broadly covered up several issues and did a long forecast focusing on electricity. Their work was a helpful tool for policy adaption on electricity generation, distribution, and management as a short-run solution for higher economic growth. On the other side, the researcher also helped to determine a long-run solution for Bangladesh by adequate investment for electricity supply relates to GDP growth.

Islam et al. (2010) also used time series models to analyse the trend of electricity generation and forecasting electricity demand in Bangladesh up to 2020. They have used the past 28 years of data (1981-2008) and forecast long-term demands for 12 years (2009-2020). Their forecasted total electricity demand for 2020 is 13916 MW. Rahman et al. (2016) did a long-term energy demand forecasting with the time series model (Gooijer \& Hyndman, 2006) using an exponential smoothing method (Maçairaa et al., 2015). It has used electricity demand data from the year 1990 to 2010. The energy demand from the year 2011 to 2040 was forecasted with time series on SPSS statistics. The MAPE of this energy consumption forecast for the year only 2012 was found $5.68 \%$, low enough to denote the accuracy of the time series model for energy demand forecasting. It can be highlighted that the available researches and reports for forecasting energy in Bangladesh mostly covered energy sources, the use of energy, and energy demand. There is no research found to be discussed particularly in the long-term per capita electricity consumption for Bangladesh which is a prime concern for the policymaker to meet the generation challenges to obtain SDGs.

In this study, actual historical demand data or consumption per capita of the past 43 years ranged from 1976/77 to 2018/19 (Bangladesh Power Development Board, 2019), has been used in different time series forecasting models (Tirkeş et al., 2017). The errors of the models are estimated to determine the best fit time series model (Towards Data Science, 2019) that coincides nearly with the actual historical data. Later, the best fit time series model has used to forecast future electricity consumption per capita for the next 22 years (FY 2019/20-FY 2040/41) to provide an energy prediction guideline to the policymaker. The accuracy of the best fit time series forecasting model has also been discussed.

\section{METHODOLOGY}

In this anticipated work, the time series forecasting model has been used to analyse the historical data collected from the Bangladesh government authenticated annual report of FY 2018/19 published by BPDB (Bangladesh Power Development Board, 2019). The data set contains electricity consumption per capita from the FY 1976/77 to FY 2018/19 as of the latest presented in Table 1. Electricity consumption was found to be increasing each year with an upward trend for most of the years except for some years with a little downward trend. For the collected data in Table 1, different time series models were applied namely as Moving Average 
(MA) model, Single Exponential Smoothing (SES) model, Double Exponential Smoothing (DES) model, Winter's Multiplicative and Additive model, Decomposition Multiplicative and Additive model, Linear Trend model, Quadratic Trend model, Exponential Trend model, S Curve Trend Analysis model, and Autoregressive Integrated Moving Average (ARIMA) model.

The forecasting errors of each time series model were evaluated and compare the performance of the models for electricity consumption per capita from the year 1976/77 to
2018/19 for Bangladesh. This model evaluation gave the best fit model with a lower forecasting error of the actual historical data. Using the best fit time series model, possible electricity consumption per capita was forecasted for the FY 2019/20 to FY 2040/41 that is the anticipated timeline to achieve the Vision-2041 (Bangladesh Development Update, 2019) of Bangladesh. The model is expected to provide more conclusive results than the other estimation done partially for different parts of Bangladesh.

Table 1. Electricity consumption per capita for FY 1976/77 to FY 2018/19 (Bangladesh Power Development Board, 2019)

\begin{tabular}{llllllll}
\hline Fiscal Year (FY) & $1976 / 77$ & $1977 / 78$ & $1978 / 79$ & $1979 / 80$ & $1980 / 81$ & $1981 / 82$ & $1982 / 83$ \\
Consumption per capita (kWh) & 12.39 & 14.39 & 16.13 & 16.04 & 19.43 & 22.07 & 25.49 \\
\hline Fiscal Year (FY) & $1983 / 84$ & $1984 / 85$ & $1985 / 86$ & $1986 / 87$ & $1987 / 88$ & $1988 / 89$ & $1989 / 90$ \\
Consumption per capita (kWh) & 28.12 & 28.96 & 33.07 & 33.81 & 35.77 & 43.49 & 42.6 \\
\hline Fiscal Year (FY) & $1990 / 91$ & $1991 / 92$ & $1992 / 93$ & $1993 / 94$ & $1994 / 95$ & $1995 / 96$ & $1996 / 97$ \\
Consumption per capita (kWh) & 44.04 & 53.7 & 60.02 & 64.08 & 71.32 & 75.88 & 78.9 \\
\hline Fiscal Year (FY) & $1997 / 98$ & $1998 / 99$ & $1999 / 00$ & $2000 / 01$ & $2001 / 02$ & $2002 / 03$ & $2003 / 04$ \\
Consumption per capita (kWh) & 80.44 & 88.69 & 95.85 & 106.08 & 113.8 & 122.43 & 133.11 \\
\hline Fiscal Year (FY) & $2004 / 05$ & $2005 / 06$ & $2006 / 07$ & $2007 / 08$ & $2008 / 09$ & $2009 / 10$ & $2010 / 11$ \\
Consumption per capita (kWh) & 139.68 & 150.22 & 149.97 & 158.2 & 165.32 & 170.27 & 180.08 \\
\hline Fiscal Year (FY) & $2011 / 12$ & $2012 / 13$ & $2013 / 14$ & $2014 / 15$ & $2015 / 16$ & $2016 / 17$ & $2017 / 18$ \\
Consumption per capita (kWh) & 197.72 & 213.15 & 232.56 & 249.16 & 281.36 & 308.22 & 335.99 \\
\hline Fiscal Year (FY) & $2018 / 19$ & & & & & & \\
Consumption per capita (kWh) & 374.62 & & & & &
\end{tabular}

\section{DATA ANALYSIS AND RESULTS}

Time series forecasting of the collected historical selected data found from the Government source of Bangladesh was placed in the Minitab 17 to determine the best method. The best fit time series model was decided based on the accuracy parameter of the historical data. The error provided by the different approaches of the time series model for the actual historical data has been compared. To be mentioned that, forecasting accuracy refers to the least forecasting deviation between the actual and forecasted value, which also means least forecasting error. In this anticipated forecasting, we have used three forecasting error determinants namely Mean Absolute \% Error (MAPE), Mean Absolute Deviation (MAD), Mean Squared Error (MSE).

They were calculated by the following relations as presented below:

$$
\begin{aligned}
\text { MAPE } & =\frac{\sum\left(\text { Actual }_{t}-\text { Forecast }_{t}\right) / \text { Actual }_{t}}{n} \\
\text { MAD } & =\frac{\sum \mid \text { Actual }_{t}-\text { Forecast }_{t} \mid}{n} \quad \text { and } \\
\text { MSD } & =\frac{\sum\left(\text { Actual }_{t}-\text { Forecast }_{t}\right)^{2}}{n-1} .
\end{aligned}
$$

where, Actual $_{t}=$ Actual value at time period $t$, Forecast t $_{t}=$ Forecasted value at time period $t, n=$ Specific number of time periods. However, MAD and MSD are selected based on the lowest MAPE.

Below, forecasting errors were presented that were obtained by the set of time series models for the actual historical data (FY 1976/77 - FY 2019/20) to determine the best fit time series model with better accuracy. 


\section{A. Moving Average}

In this moving average method, eleven moving average value was computed using a different value of the forecasting period $(n)$. Error determinants of eleven sets $(n=2,3 \ldots, 12)$ were calculated and the lowest values of MAPE, MAD, and MSD are found when the forecasting period is $2(n=2)$. The values of MAPE, MAD, and MSD are ranged between 11.06$35.76,12.73-51.71$, and 313.69-3781.95, respectively. The deviation between actual consumption data and forecasted data for the forecasting period $(n=2)$ of the moving average method is shown in Figure 2.

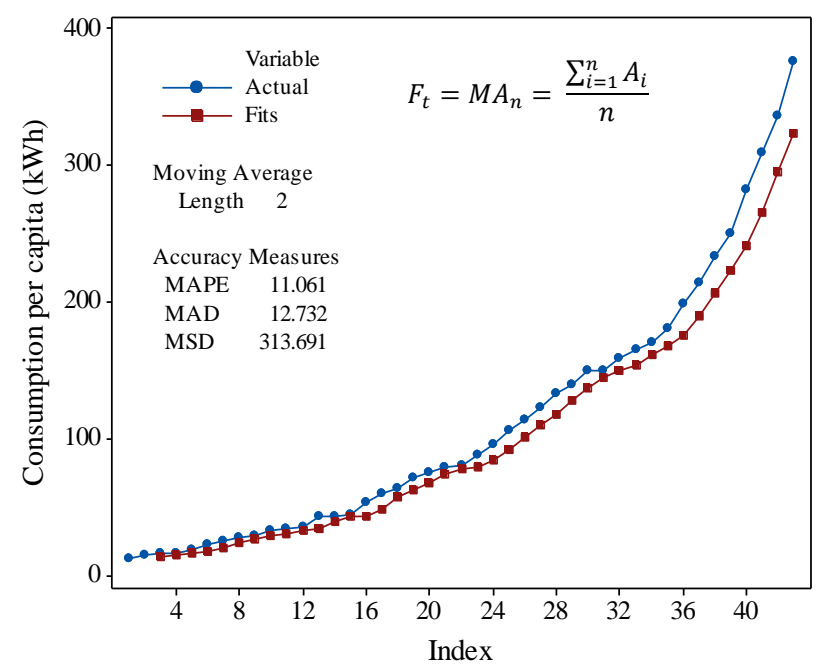

Figure 2. Moving average plot for forecasting period $(n=2)$

\section{B. Single Exponential Smoothing}

It is suggested that if time series varies in the base level, single exponential smoothing is one of the best options for the estimation of the upcoming time series value. In this method, the exponential smoothing constant $(\alpha)$ is an important consideration. MAPE, MAD, and MSD were calculated using nine values of $\alpha$ within the range (o< $\alpha<1)$ to find the optimum value of the $\alpha$. The least forecasting errors were obtained for the highest value of $\alpha=$ o.9. The values obtained for MAPE, MAD, and MSD are ranged between 8.99-37.71, 9.34-46.83, and 178.30-3925.04, respectively.

The variation between the actual and predicted data for smoothing constant $\alpha=0.9$ has presented in Figure 3 .

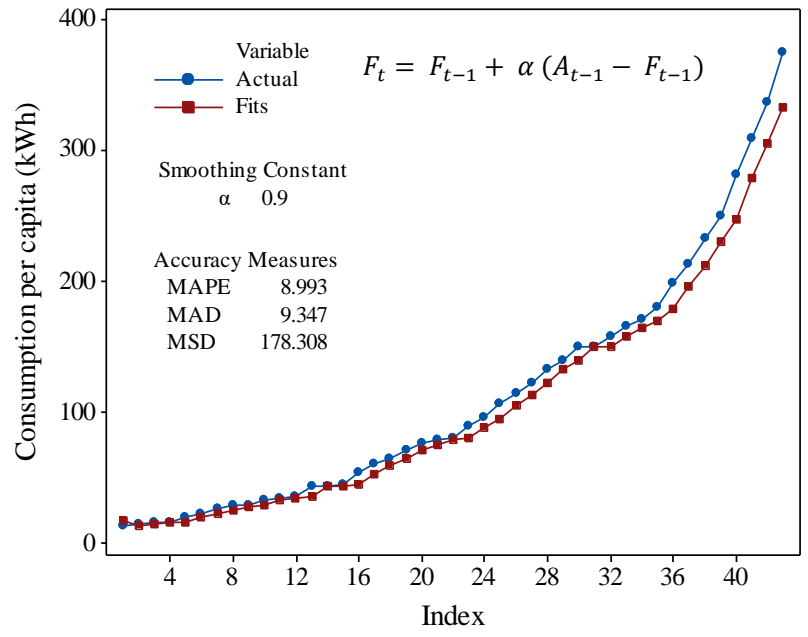

Figure 3. Single exponential smoothing plot

\section{Double Exponential Smoothing}

There are two smoothing constants in the double exponential smoothing model namely level $(\alpha)$ and trend $(\gamma)$. Forecasting error sets were calculated by using the value of $\alpha$ and $\gamma$ ranged between 0.1-0.3 for both. Nine trials were taken, and errors were ranged for MAPE, MAD, and MSD between 30.7546.80, 12.40-26.16, and 278.40-1169.34, respectively. The lowest errors were obtained for MAPE at $\alpha=0.3$ and $\gamma=0.1$, for MAD and MSE at $\alpha=0.3$ and $\gamma=0.3$. To obtain the main selection parameter MAPE, we have selected the MAPE, MAD, and MSD for $\alpha=0.3$ and $\gamma=0.1$. The graphical illustration of Figure 4 reveals that actual data and forecasted data coincide for some periods.

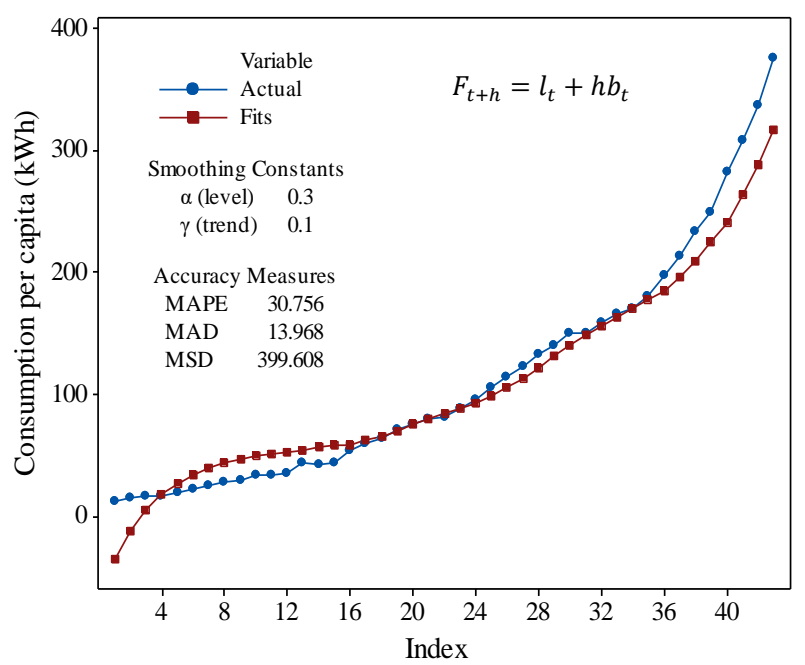

Figure 4. Double exponential smoothing plot

The equation is shown in Figure 4 is the equation for double exponential smoothing. So, forecasting equation, $F_{t+h}=l_{t}+$ $h b_{t}$ where the Level equation is $l_{t}=\alpha y_{t}+(1-\alpha)\left(l_{t-1}+\right.$ $b_{t-1}$ and Trend equation is $b_{t}=\gamma\left(l_{t}-l_{t-1}\right)+(1-\gamma) b_{t-1}$. 
$F_{t+h}$ is the forecast for period $h, l_{t}$ is the estimated time of level at time $t, y_{t}$ is the forecast at time $t, l_{t-1}$ is the previous estimate level time, $b_{t}$ is the estimated time of trend at time $t, b_{t-1}$ is the previous estimate time trend, $\alpha$ is the smoothing constant for level $(0<\alpha<1), \gamma$ is the smoothing constant for trend $(0<\gamma<1)$.

\section{Winter Model}

Winter's model consists of two types of models namely multiplicative and additive, and they were used to find out the error set. Winter time series model considers an additional smoothing constant seasonality $(\delta)$ with the regular smoothing constant of level $(\alpha)$ and trend $(\gamma)$ in respect to the double exponential smoothing model. For all of the smoothing constants $\alpha, \gamma$, and $\delta$ in the Winter time series model, the values of the constants ranged between 0.1-0.3. A total of 27 trials were considered. The values of MAPE, MAD, and MSD in the Winter Multiplicative model were ranged between 11.12-16.43, 9.35-18.78, and 154.37-678.08, respectively. The lowest value of trial for MAPE in Winter multiplicative was 11.12, for MAD was 9.35 and for MSD was 154.37 at $\alpha=0.3, \gamma=0.2, \delta=0.3$.

On the other hand, the values of MAPE, MAD, and MSD in the Winter additive model were ranged between 19.51-25.86, 12.57-23.54, and 224.25-975.91 respectively. The lowest value for Winter-additive MAPE was 19.51 at $\alpha=0.3, \gamma=0.2, \delta=$ 0.3; for MAD was 12.57 at $\alpha=0.3, \gamma=0.3, \delta=0.3$; and for MSD was 224.25 at $\alpha=0.3, \gamma=0.3, \delta=0.3$. Figure 5(a) and 5(b) presents the comparison of actual data and forecasted data of multiplicative and additive models respectively based on MAPE's lowest value for the smoothing constant $\alpha=0.3$, $\gamma=0.2, \delta=0.3$, where Winter multiplicative model was shown better accuracy than the additive model.

The equation is shown in Figures 5(a) and 5(b) are the equation for the Winter Multiplicative and Additive model. The forecasting equation for the Winter Multiplicative model is $F_{t}=\left(L_{t-1}+T_{t-1}\right) S_{t-p}$ where the Level equation is $L_{t}=$ $\alpha\left(\frac{y_{t}}{s_{t-p}}\right)+(1-\alpha)\left(L_{t-1}+T_{t-1}\right)$. Trend equation is $T_{t}=$ $\gamma\left(L_{t}-T_{t-1}\right)+(1-\gamma) T_{t-1}$. The Seasonal equation is expressed as $S_{t}=\delta\left(\frac{y_{t}}{L_{t}}\right)+(1-\delta) S_{t-p}$.

The forecasting equation for the Winter additive model is, $F_{t}=L_{t-1}+T_{t-1}+S_{t-p}$, where the Level equation is $L_{t}=$
$\alpha\left(y_{t}-S_{t-p}\right)+(1-\alpha)\left(L_{t-1}+\right.$,Trend equation, $T_{t}=\gamma\left(L_{t}-\right.$ $\left.T_{t-1}\right)+(1-\gamma) T_{t-1}$ Seasonal equation is $S_{t}=\delta\left(y_{t}-L_{t}\right)+$ $(1-\delta) S_{t-p}$, where, $F_{t}=$ forecast of one period advanced at time $t, L_{t}$ is the estimated time of level at time $t, T_{t}$ is the estimated time of trend at time $t, S_{t}$ is the estimated time of seasonal at time $t . y_{t}$ is data value at time $t, p$ is seasonal period, $\alpha$ is the smoothing constant for level $(0<\alpha<1), \gamma$ is the smoothing constant for trend (o $<\gamma<1$ ), $\delta$ is the smoothing constant for seasonality $(0<\alpha<1)$.
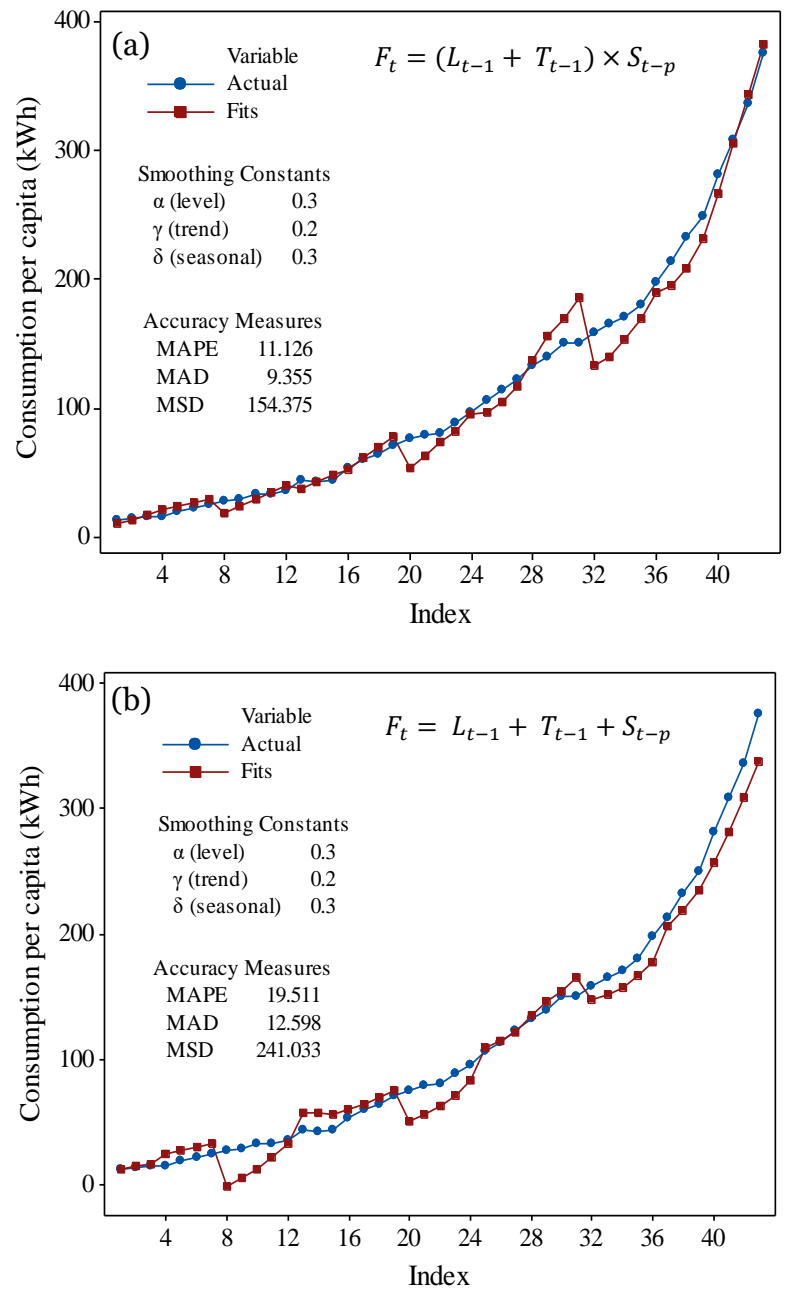

Figure 5. Winter model plot (a) multiplicative model, and

(b) additive model

\section{E. Decomposition Model}

The decomposition model also consists of two models namely multiplicative and additive. The MAPE, MAD, and MSD found for the multiplicative model are 49.653, 25.323, 970.679, respectively and for the additive model are 50.230, 25.850, 1039.580. The analysis result for the multiplicative and additive model is shown in Figures 6(a) and 6(b), respectively. Each figure represents that actual and 
forecasted values are almost same for the most of the period whereas trend value follows different from the actual and forecasted values.
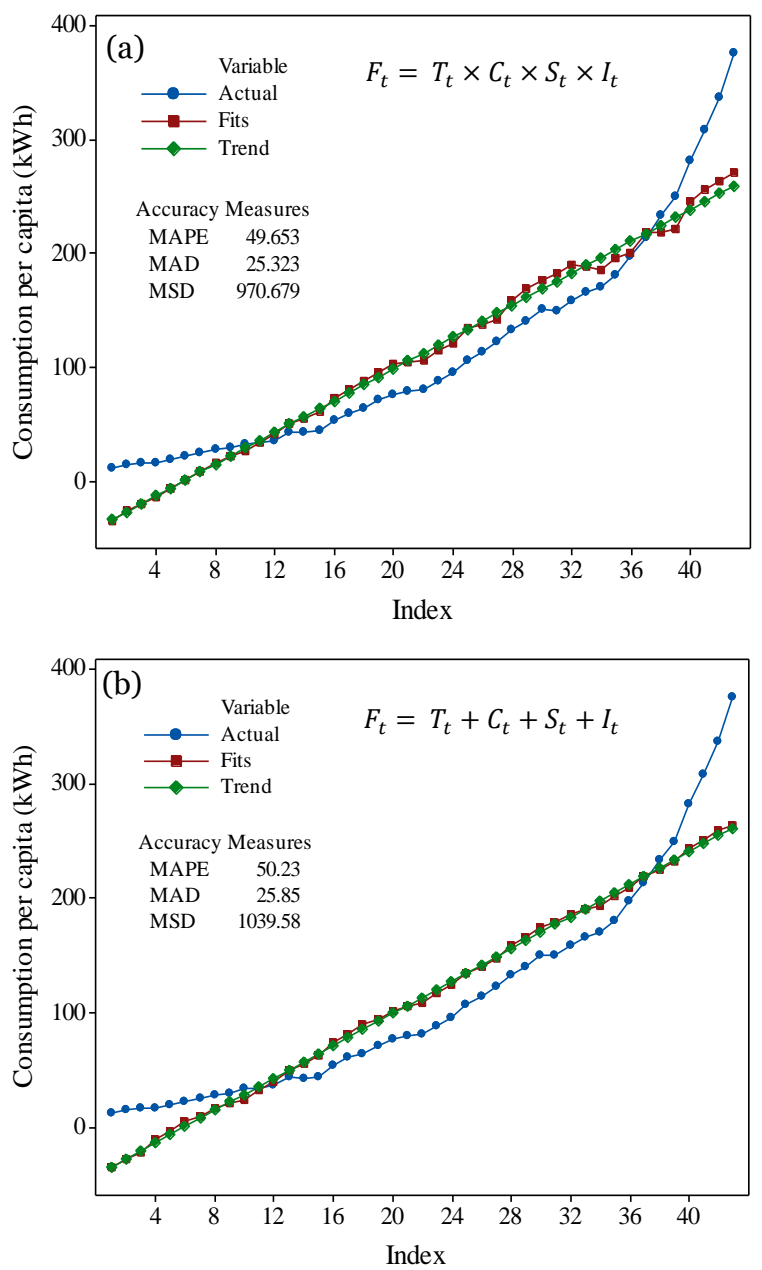

Figure 6. Decomposition model plot (a) multiplicative model, and (b) additive model

The equation is shown in Figures 6(a) and 6(b) are the equation of decomposition multiplicative and additive model respectively. So, the equation for the decomposition multiplicative model is, $F_{t}=T_{t} C_{t} S_{t} I_{t}$ and additive model is, $F_{t}=T_{t}+C_{t}+S_{t}+I_{t}$, where, $F_{t}$ is the forecasting series, $T_{t}$ is the long-term trend, $C_{t}$ is the cycle, $S_{t}$ and $I_{t}$ are expressed in terms of trend $T_{t}$ and cycle $C_{t}$ in the Multiplicative model, Whereas $S_{t}$ is seasonality and $I_{t}$ is Irregularity in the additive model.

\section{F. Trend Analysis}

Four types of trends were analysed namely linear, quadratic, exponential growth, and S curve. Below the analysis, the results were shown for all types of trend analysis in Figures 7 , 8, 9, and 10. Over the past 43 years (FY 1976/77-2018/19) of electricity consumption, the linear trend was found to be like Equation (1). In Figure 7, the actual and forecasted electricity consumption for linear trend analysis is shown. Quadratic trend analysis presented in Figure 8 shows a better result than linear trend analysis. The Equation (2) shows the quadratic trend mathematical form over the 43 years of data (FY 1976/77-2018/19).

$$
\begin{gathered}
F_{t}=-42.1+7.058 \times t \\
F_{t}=29.72-2.518 \times t+0.2176 \times t^{2}
\end{gathered}
$$

However, Exponential growth depicts a better result than the linear and quadratic trend. The MAPE, MAD, and MSD are found to be $8.36,8.32$, and 128.21 , respectively. The Equation (3) was found for exponential growth trend analysis. A comparison of forecasting error sets of Exponential growth trends of actual data and forecast data is shown in Figure 9.

$$
F_{t}=14.5268 \times\left(1.07852^{t}\right)
$$

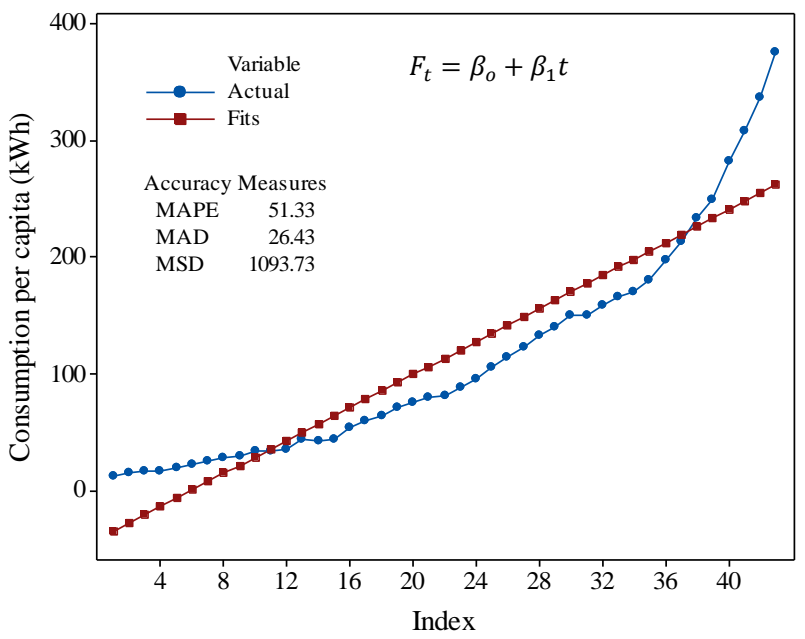

Figure 7. Linear trend plot

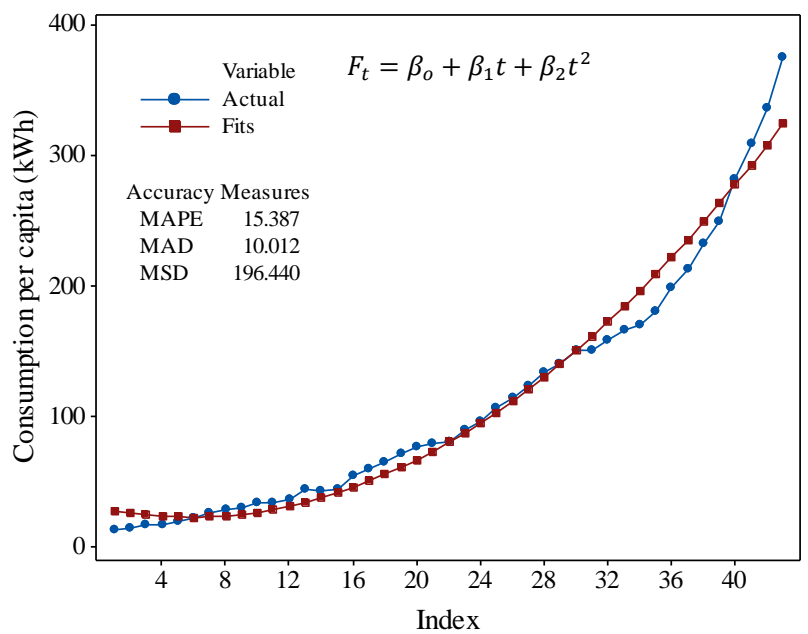

Figure 8. Quadratic trend plot 


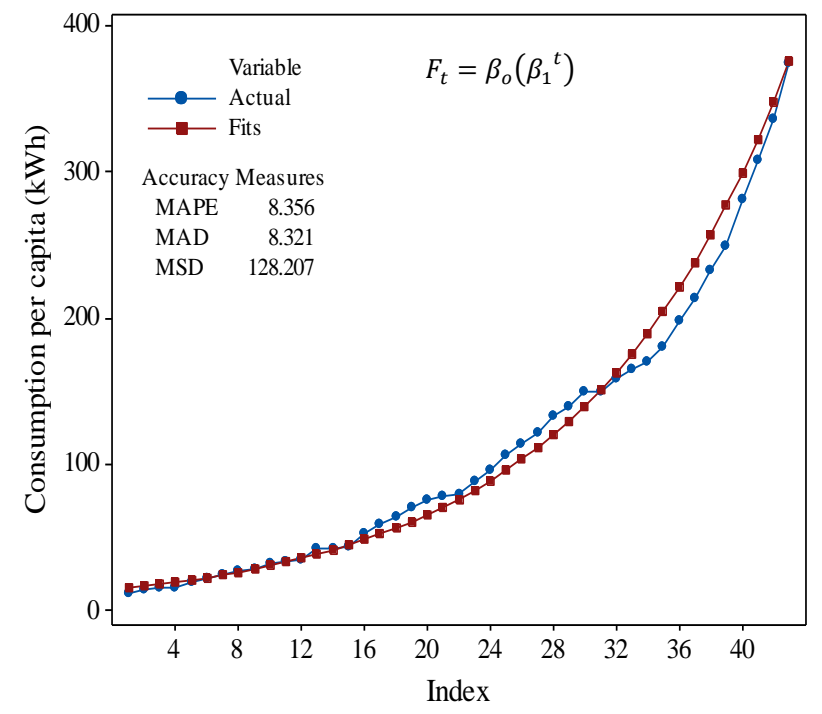

Figure 9. Exponential growth trend plot

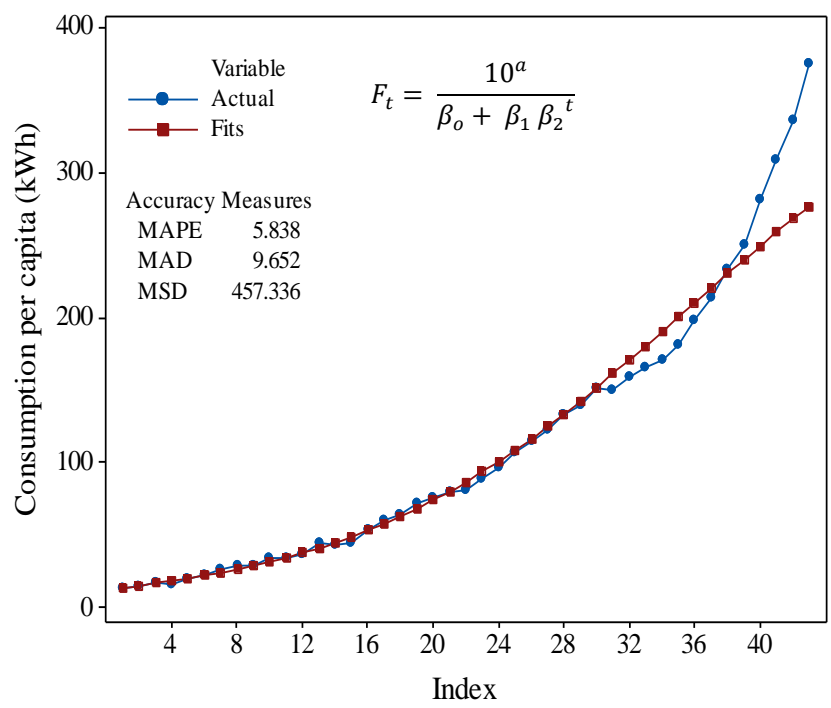

Figure 10. S curve trend plot

Among all the trend analyses $\mathrm{S}$ curve model provides the lowest error set in all respect of MAPE, MSD, and MAD. Below the analysis results are shown in Figure 10 and Equation (4) for the $\mathrm{S}$ curve is as follows:

$$
F_{t}=\frac{10^{4}}{\left(24.7027+797.910 \times\left(0.906118^{t}\right)\right)}
$$

\section{G. ARIMA}

ARIMA is a powerful model that explains not only stationary time series but also non-stationary time series is named as an autoregressive integrated moving average (ARIMA) process. An ARIMA process order of $(\mathrm{p}, \mathrm{q}, \mathrm{d})$ is defined by the following $\nabla^{d} z_{t}=\varphi_{1} z_{t-1}+\cdots+\varphi_{p} z_{t-p}+a_{t}-\Theta_{1} a_{t-1}-\cdots-$
$\Theta_{q} a_{t-q}$ where, $\nabla^{d}$ represents the difference in time series, $z_{t}=$ times series data at time period $t, \varphi_{1} \ldots \ldots \varphi_{p}$ are autoregressive parameters $((p \neq 0)$ and $(p \leq 5)), \Theta_{1} \ldots \ldots \Theta_{q}$ are moving average parameters $((q \neq 0)$ and $(q \leq 5)), a_{t}$ is a series of unknown random errors or residuals assumed by the normal distribution, $z_{t-1} \ldots z_{t-p}$ is the $p$ past function used for the predicts of the current value $z_{t}, a_{t-1} \ldots a_{t-q}$ is the $q$ past function used for the predicts of the current value $a_{t}$. MAPE, MAD, and MSD were measured by the ARIMA time series model and the value obtained is 4.50, 3.23, and 15.40, respectively. In ARIMA, we have taken 30 trials for various combinations of $(p, q, d)$ and the lowest MAPE, MAD, and MSD has been found at $(5,0,5)$. Forecasting error under ARIMA and Chi-Square statistic is shown in Table 2 and 3, respectively. Figure 11 shows the residual plot for the electricity consumption per capita of the ARIMA model. Figure 11(a) represents that no other pattern is observed in residual values and normally distributed, Figure 11(b) depicts fitted value that means the forecasted value is aligned with the residual values, Figure 11(c) shows the occurrence of residuals, and Figure 11(d) presents the observational order of residuals.
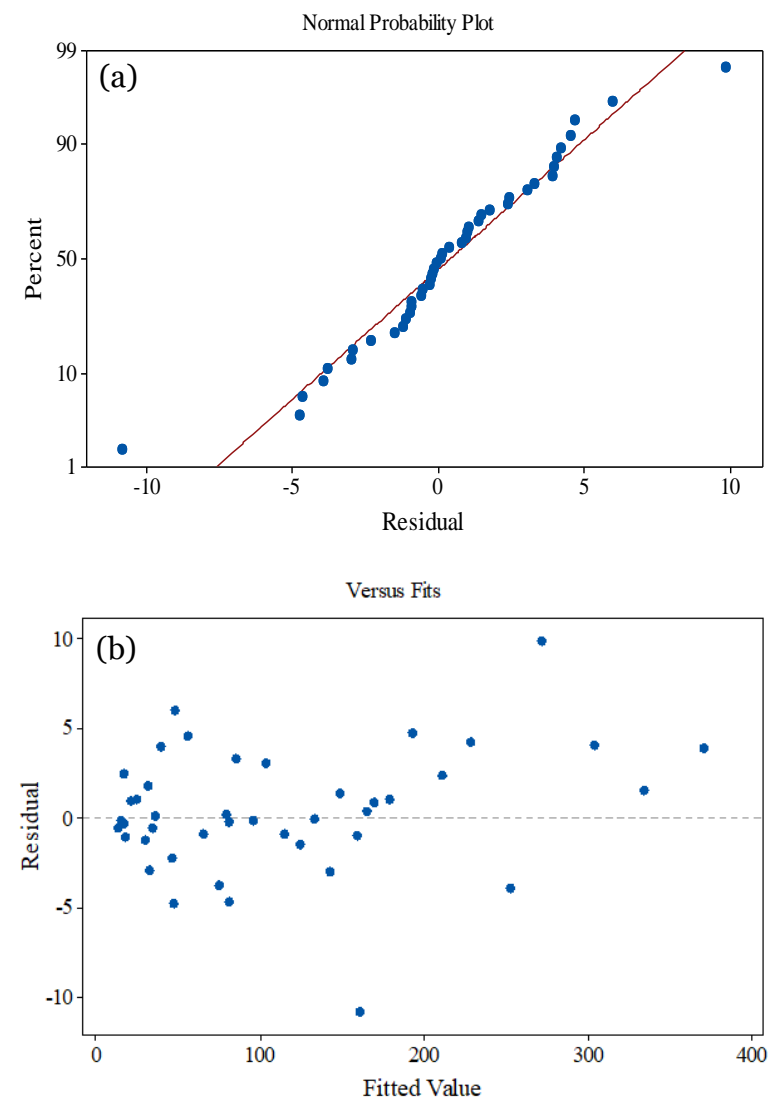

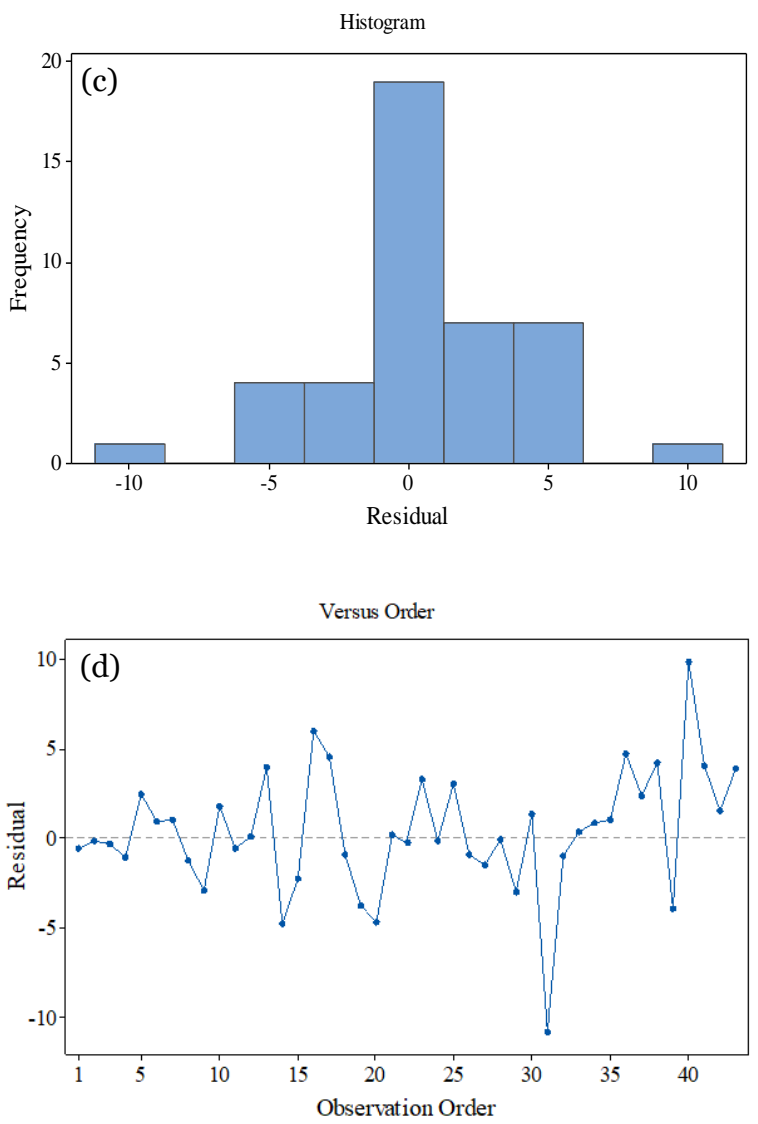

Figure 11. Residual plots for per capita consumption in ARIMA

Table 2. Forecasting errors under ARIMA

\begin{tabular}{ccc}
\hline MAPE & MAD & MSD \\
\hline 4.502 & 3.226 & 15.396 \\
\hline
\end{tabular}

Table 3. (Ljung-Box) Chi-Square statistic

\begin{tabular}{cccc}
\hline Lag & Chi-Square & DF & $\begin{array}{c}\text { P- } \\
\text { Value }\end{array}$ \\
\hline 12 & 5.0 & 2 & 0.081 \\
24 & 13.2 & 14 & 0.514 \\
36 & 20.0 & 26 & 0.790 \\
\hline
\end{tabular}

Based on the residual plot and accuracy, it can be concluded that ARIMA $(5,0,5)$ model is suitable for forecasting per capita electricity consumption. To overview the MAPE, MAD, and MSD values obtained by the different forecasting methods, we have summarised all the forecasting errors computed using the time series model in Table 4. The comparison shows that MAPE, MAD, MSD obtained by ARIMA among the time-series forecasting model is the lowest error set that complies with our actual historical data. Therefore, the ARIMA $(5,0,5)$ model can be applied for forecasting the electricity consumption per capita for the next 22 years' data (Up to 2041) with the highest accuracy.

Table 4. Forecasting accuracy over 43 periods (FY 1976/772018/19) (descending order of MAPE)

\begin{tabular}{lccc}
\hline Forecasting methods & MAPE & MAD & MSD \\
\hline Trend analysis linear & 51.33 & 26.43 & 1093.73 \\
$\begin{array}{l}\text { Decomposition-additive } \\
\text { model }\end{array}$ & 50.23 & 25.85 & 1039.58 \\
Decomposition-multiplicative & & & \\
model & 49.65 & 25.32 & 970.68 \\
Double exponential & & & \\
smoothing & 30.76 & 13.97 & 399.61 \\
Winter additive & & & \\
Trend analysis quadratic & 19.51 & 12.60 & 241.03 \\
Winter multiplicative & 11.13 & 9.36 & 154.38 \\
Moving average & 11.06 & 12.73 & 313.69 \\
Single exponential smoothing & 8.99 & 9.35 & 178.31 \\
Trend analysis exponential & 8.36 & 8.32 & 128.21 \\
growth & & & \\
Trend analysis S curve & 5.84 & 9.65 & 457.34 \\
ARIMA & 4.50 & 3.23 & 15.40 \\
\hline
\end{tabular}

\section{H. Forecasting for Vision-2041}

To make the forecasting data resourceful to the Bangladesh Government as well as to the other energy-related institutions, the maximum forecasting year was set FY 2040/41, in which the Bangladesh Government planned to reach high-income country status. It will help in forecasting electricity to meet the SDGs goals also. However, per capita electricity consumption was forecasted with all the time series models to broaden the acceptability of the resource and to facilitate a comparison among the other time series model and our suggested best fit time series model determined through the actual historical data. The forecasting data obtained by using the time series model is shown in Table 5 for the next 22 periods of electricity consumption per capita with all the model equations described above. The first forecasting period has started at 44 (FY 2019/20) and ends at period 65 (FY 2040/41) though a wider forecast period is also possible. 
ASM Science Journal, Volume 16, 2021

Table 5. Forecasting for next 22 periods (FY 2019/20 to FY 2040/41)

\begin{tabular}{|c|c|c|c|c|c|c|c|c|c|c|c|}
\hline \multirow[b]{2}{*}{ Year } & \multirow{2}{*}{$\begin{array}{c}\text { Forecast } \\
\text { Period }\end{array}$} & \multirow{2}{*}{$\begin{array}{c}\text { Double } \\
\text { exponential } \\
\text { smoothing }\end{array}$} & \multicolumn{2}{|c|}{ Winters Model } & \multicolumn{2}{|c|}{ Decomposition } & \multicolumn{4}{|c|}{ Trend Analysis } & \multirow[b]{2}{*}{ ARIMA } \\
\hline & & & Multiplicative & Additive & Multiplicative & Additive & Linear & Quadratic & $\begin{array}{l}\text { Exponential } \\
\text { growth }\end{array}$ & $\begin{array}{c}\mathbf{S} \\
\text { Curve }\end{array}$ & \\
\hline $2019 / 20$ & 44 & 284.98 & 324.40 & 340.18 & 276.90 & 270.32 & 268.46 & 340.28 & 404.23 & 284.67 & 411.28 \\
\hline $2020 / 21$ & 45 & 295.43 & 331.23 & $349 \cdot 31$ & 271.09 & 274.72 & $275 \cdot 51$ & 357.13 & $435 \cdot 97$ & 292.83 & 446.69 \\
\hline $2021 / 22$ & 46 & 305.88 & 342.09 & 358.02 & 265.05 & 276.74 & 282.57 & 374.42 & 470.20 & 300.64 & 486.01 \\
\hline $2022 / 23$ & 47 & 316.33 & 361.07 & 369.90 & 277.07 & 285.41 & 289.63 & 392.14 & 507.12 & 308.08 & 528.58 \\
\hline $2023 / 24$ & 48 & 326.78 & 390.63 & 384.66 & 280.58 & 292.72 & 296.69 & 410.30 & 546.94 & 315.15 & 572.43 \\
\hline $2024 / 25$ & 49 & 337.23 & 402.20 & 408.56 & 303.18 & 303.13 & 303.75 & 428.89 & 589.89 & 321.85 & 618.33 \\
\hline $2025 / 26$ & 50 & 347.68 & 416.07 & 424.43 & 300.05 & 309.49 & 310.81 & 447.92 & 636.21 & 328.16 & 668.15 \\
\hline $2026 / 27$ & 51 & 358.13 & 433.66 & 439.49 & 301.89 & 316.02 & 317.86 & 467.39 & 686.16 & 334.10 & 721.48 \\
\hline $2027 / 28$ & 52 & 368.58 & 475.23 & 461.00 & 331.25 & 327.54 & 324.92 & 487.29 & 740.04 & 339.67 & 777.88 \\
\hline $2028 / 29$ & 53 & 379.03 & 516.27 & 478.93 & 343.07 & 335.13 & 331.98 & 507.62 & 798.15 & 344.88 & 837.99 \\
\hline $2029 / 30$ & 54 & 389.48 & 559.89 & 497.22 & 350.96 & 343.06 & 339.04 & 528.39 & 860.82 & 349.74 & 902.74 \\
\hline 2030/31 & 55 & 399.92 & 611.99 & 516.59 & 356.95 & 347.72 & 346.09 & 549.60 & 928.41 & 354.27 & 972.08 \\
\hline $2031 / 32$ & 56 & 410.37 & 521.16 & 506.40 & 364.01 & 354.94 & 353.15 & 571.24 & 1001.31 & 358.47 & 1046.16 \\
\hline $2032 / 33$ & 57 & 420.82 & 522.47 & 515.53 & 354.19 & 359.34 & 360.21 & $593 \cdot 31$ & 1079.94 & 362.36 & 1125.55 \\
\hline 2033/34 & 58 & 431.27 & 530.52 & 524.25 & 344.28 & 361.36 & 367.27 & 615.82 & 1164.73 & 365.97 & 1210.88 \\
\hline $2034 / 35$ & 59 & 441.72 & 551.24 & 536.13 & 357.88 & 370.03 & 374.33 & 638.77 & 1256.19 & 369.29 & 1302.40 \\
\hline $2035 / 36$ & 60 & 452.17 & 587.71 & 550.88 & 360.47 & $377 \cdot 33$ & 381.39 & 662.15 & 1354.83 & 372.36 & 1400.56 \\
\hline $2036 / 37$ & 61 & 462.62 & 596.93 & 574.78 & 387.50 & 387.75 & 388.44 & 685.97 & 1461.21 & 375.18 & 1505.93 \\
\hline $2037 / 38$ & 62 & 473.07 & 609.71 & 590.65 & 381.61 & 394.10 & 395.50 & 710.22 & 1575.94 & 377.78 & 1619.15 \\
\hline $2038 / 39$ & 63 & 483.52 & 627.95 & 605.71 & 382.13 & 400.64 & 402.56 & 734.91 & 1699.69 & 380.16 & 1740.70 \\
\hline $2039 / 40$ & 64 & 493.97 & 680.49 & 627.22 & 417.39 & 412.16 & 409.62 & 760.03 & 1833.15 & 382.35 & 1871.24 \\
\hline $2040 / 41$ & 65 & 504.42 & 731.50 & 645.15 & 430.40 & 419.74 & 416.68 & 785.59 & 1977.09 & $384 \cdot 35$ & 2011.47 \\
\hline
\end{tabular}


Table 6. Forecasting accuracy for 65 periods (FY 1976/77 to FY 2040/41) (descending order of MAPE)

\begin{tabular}{|c|c|c|c|}
\hline Forecasting methods & MAPE & MAD & MSD \\
\hline $\begin{array}{ll}\text { Double } & \text { exponential } \\
\text { smoothing } & \end{array}$ & 41.16 & 19.63 & 955.43 \\
\hline Trend analysis linear & 33.95 & 17.48 & 723.55 \\
\hline $\begin{array}{l}\text { Decomposition- } \\
\text { multiplicative model }\end{array}$ & 33.08 & 17.69 & 628.04 \\
\hline $\begin{array}{l}\text { Decomposition-additive } \\
\text { model }\end{array}$ & 33.04 & 17.26 & 674.96 \\
\hline Winter additive & 12.81 & 9.25 & 187.19 \\
\hline Trend analysis quadratic & 10.17 & 6.62 & 129.95 \\
\hline Winter multiplicative & 6.62 & 11.69 & 305.59 \\
\hline $\begin{array}{l}\text { Trend analysis exponential } \\
\text { growth }\end{array}$ & $5 \cdot 52$ & $5 \cdot 50$ & 84.81 \\
\hline Trend analysis S curve & 3.89 & 6.59 & 311.97 \\
\hline ARIMA & 2.96 & 2.665 & 11.745 \\
\hline
\end{tabular}

After forecasted the data for the next 22 periods (FY 2019/20 to FY 2040/41), the total periods for the data is 65 (FY 1976/77 to FY 2040/41) consists of 43 periods for actual historical data (FY 1976/77 to 2018/19) and 22 periods for forecasted data (FY 2019/20 to FY 2040/41). The forecasting accuracy for the data of a total of 65 periods (FY--1976/77 to FY 2040/41) has been calculated for all the time series models except the moving average and single exponential smoothing. The forecasting accuracy for 65 periods (FY 1976/77 to FY 2040/41) is shown in Table 6 for comparison. Since ARIMA has appeared as the best fit time series forecasting method, it can be used for forecasting long-term electricity consumption per capita in Bangladesh in the future.

\section{DISCUSSION}

Based on the actual historical demand data or consumption per capita over the past 43 years ranged FY 1976/77 to FY 2018/19 (Bangladesh Power Development Board, 2019), demand or consumption per capita for a long period of time has been successfully done in this work for Bangladesh. The forecasted time period is 22 years (FY 2019/20 to FY 2040/41) to link the forecasting data with the Vision-2041 goals of Bangladesh. ARIMA time series model was applied to forecast the consumption per capita for its accuracy with the actual historical data. For the above forecasting analysis and trials, the following points can be concluded: (a) The actual historical data for Bangladesh has always been increasing trend except for some FY with a little downward trend. Over the FY 1976/77 to FY 2018/19 tenure an overall jumped of $96.69 \%$ electricity consumption is noticeable (Table 1). The consumption is mostly satisfied by the natural gas source and furnace oil (Figure 1). The clean or alternative source of energy has no significant contribution to the energy demand.

(b) No real forecasting for future electricity consumption per capita is available. A few cases are reported for forecasting local energy consumption or short-term forecasting using the time series forecasting model.

(c) After evaluation and comparison of the different time series models, it has been verified that ARIMA is the most appropriate model among other time series models for 43 years of consumption data with MAPE, MAD, and MSD of 4.502, 3.226, and 15.396, respectively. ARIMA time series forecasting model has the lowest forecasting errors for actual historical data of 43 years (FY 1976/77 to FY 2018/19). It has appeared as the best fit model with higher forecasting accuracy.

(d) The forecasted electricity consumption per capita using ARIMA $(5,0,5)$ model in the first forecasted year is $411.28 \mathrm{kWh}$ (FY 2019/20) and for the last forecasted year (FY 2040/41) is 2011.47 kWh (Table 5). Forecasting indicates a jump of 81.38 \% electricity consumption for the next 22 years period.

(e) The forecasting accuracy or forecasting error in ARIMA is MAPE $=2.96, \mathrm{MAD}=2.67, \mathrm{MSD}=11.75$ provided in Table 6 for 65 years periods with 95 per cent confidence level (Figures 12, 13, and 14). Both the 43 years accuracy (Table 4) and 65 years accuracy (Table 6) are close. Therefore, the forecasted electricity consumption per capita will be a true resource for the Bangladesh Government. 


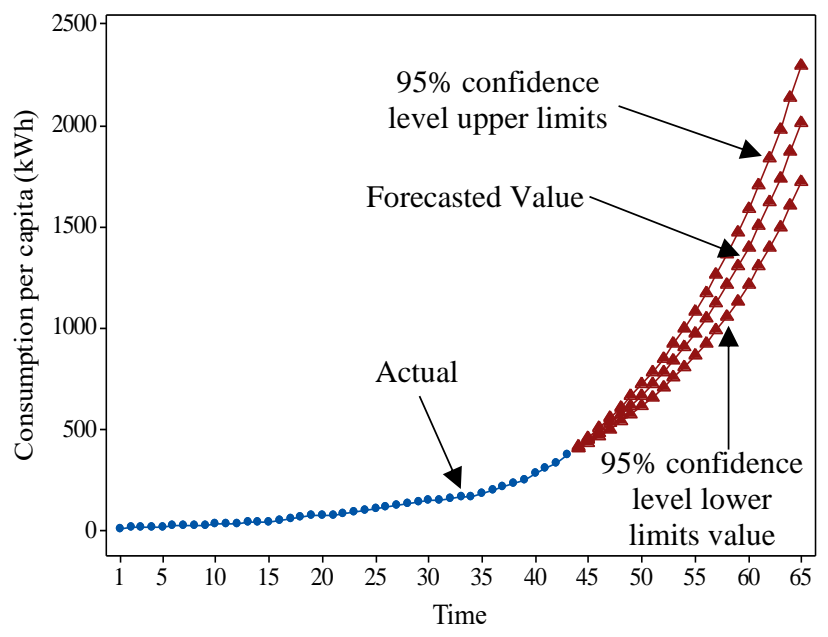

Figure 12. Forecast in ARIMA for 22 periods (FY 2019/20 to 2040/41) with $95 \%$ confidence limits

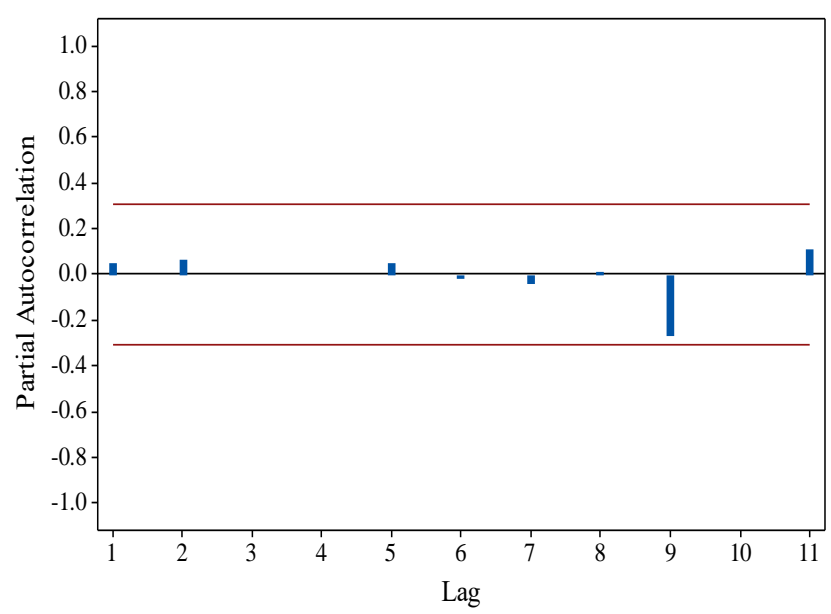

Figure 13. Partial Auto Correlation Function (PACF) residuals for consumption per capita with $5 \%$ significance limits. Red lines represent significance limits.

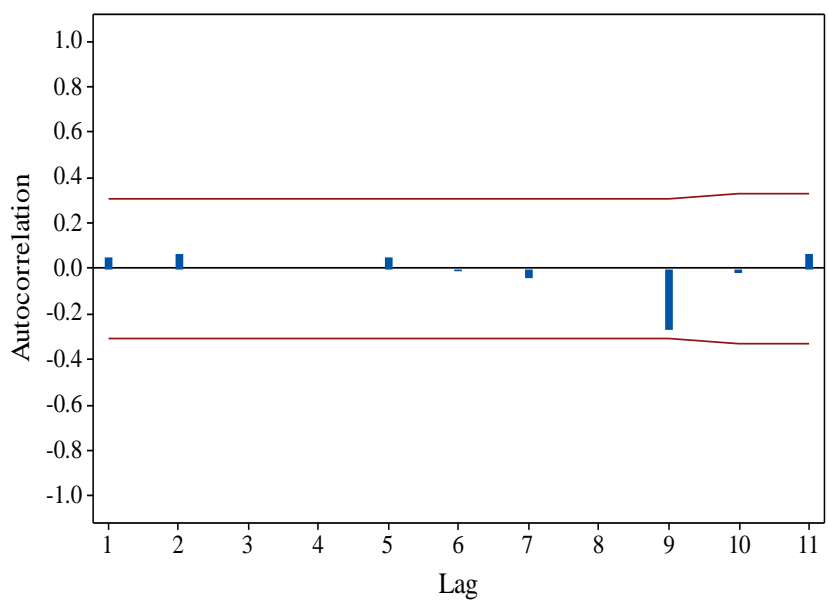

Figure 14. Auto Correlation Function (ACF) residuals for consumption per capita with $5 \%$ significance limits. Red lines represent significance limits

\section{CONCLUSIONS}

This forecasting effort for the per capita electricity consumption of Bangladesh has been successfully done by a selected time series forecasting model called ARIMA. The other time series model is also evaluated and ARIMA has been determined as the best fit time series model that coincides nearly with the actual historical data. Later, the best fit ARIMA time series model has used to forecast future electricity consumption per capita for the next 22 years (FY 2019/20 to FY 2040/41) to provide an energy prediction guideline to the policymaker. Considering the coming years of electricity consumption, we selected the most accurate forecasting methodology and forecasted electricity consumption for the next 22 years using Minitab 17. In this electricity forecasting, the highest electricity consumption has found 2011.47 kWh or 2.011 MWh/capita for the year of vision-2041 in the ARIMA model which is selected as more accurate. The electricity generation must meet up the demands as forecasted since Bangladesh Government has declared to turn Bangladesh into a middle-income country by the year 2021 and a high-income country by the year 2041 (Vison-2041) from the current status of the lower-middleincome country. Compared to some other high-income countries electricity consumption per capita in 2017 like Uruguay 3.0 MWh/capita (Electricity Consumption Per Capita of Uruguay, 2017), Panama 2.3 MWh/capita (Electricity Consumption Per Capita of Panama, 2017), and in 2018 Chile 4.1 MWh/capita (Electricity Consumption Per Capita of Chile, 2018), our forecasted highest consumption per capita for the year of 2041 is aligned and consistent with present conditions. Finally, accuracy measurement was also identified for all-time series except for moving average and single exponential smoothing over the 65 years data i.e., combined data of previous 43 years and forecasted 22 years electricity consumption data. This computed result also shows that ARIMA is the best option for the forecasting of electricity consumption per capita with MAPE, MAD, and MSD of 2.958, 2.665, and 11.745, respectively. This study will help the power sector of Bangladesh to electricity generation and facility expansion for future development. Also, future research direction could integrate total power generation based on various energy source's contributions and different sector energy consumption to forecast electricity 
consumption per capita. However, the electricity consumptions rate is increasing at an exponential rate and this research has considered the linear regression model for simplicity. Thus, forecasted data may face misalignment in some cases for long periods. Again recently, a lot of alternative non-electrical energy sources are being used that may not come under this estimation.

This forecasting effort for the per capita electricity consumption of Bangladesh has been successfully done by a. this study will help the power sector of Bangladesh to electricity generation and facility expansion for future development. Also, future research direction could integrate total power generation based on various energy sources' contributions and different sector energy consumption to forecast electricity consumptions rate is increasing at an exponential rate and this research has considered the linear regression model for simplicity. Thus, forecasted data may face misalignment in some cases for long periods. Again recently, a lot of alternative non-electrical energy sources are being used that may not come under this estimation.

\section{REFERENCES}

Acakpovi, A, Ternor, AT, Asabere, NY, Adjei, P \& Iddrisu, AS 2020, 'Time series prediction of electricity demand using adaptive neuro-fuzzy inference systems', Mathematical Problems in Engineering, vol. 2020, Article ID 4181045. https://doi.org/10.1155/2020/4181045.

Bangladesh and Asian Development Bank 2018, Asian Development Bank work in Bangladesh, retrieved from $\leq$ https://www.adb.org/countries/bangladesh/overview $>$.

Bangladesh Development Update 2019, Towards regulatory predictability, retrieved from $\leq$ http://documents.worldbank.org/curated/en/26924155 4408636618/pdf/Bangladesh-Development-UpdateTowards-Regulatory-Predictability.pdf $>$.

Bangladesh Power Development Board 2019, Annual report 2018-2019, retrieved from <http://www.bpdb.gov.bd/bpdb_new/resourcefile/annua lreports/annualreport 1574325376 Annual Report 201 8-19.pdf>.

Changhong, C, Bingyan, W, Qingyan, F, Green, C \& Streets, DG 2006, 'Reductions in emissions of local air pollutants and co-benefits of Chinese energy policy: a Shanghai case study', Energy Policy, vol. 34, no. 6, pp. 754-762. https://doi.org/10.1016/j.enpol.2004.07.007.

Campillo, J, Wallin, F, Torstensson, D \& Vassileva, I 2012, 'Energy demand model design for forecasting electricity consumption and simulating demand response scenarios in Sweden', Proceedings of the $4^{\text {th }}$ International Conference in Applied Energy, Suzhou, China, 5-8 July 2012, pp. 1-7. http://www.divaportal.org/smash/get/diva2:582603/fulltexto1.pdf.
Chujai, P, Kerdprasop, N \& Kerdprasop, K 2013, 'Time series analysis of household electric consumption with ARIMA and ARMA models', Proceedings of the International Multi Conference of Engineers and Computer Scientists (IMECS), Hong Kong, March 13-15, 2013, pp. 1-6. http://www.iaeng.org/publication/IMECS2013/IMECS20 13_pp295-300.pdf.

Deb, C, Zhang, F, Yang, J, Lee, SE \& Shah, KW 2017, 'A review on time series forecasting techniques for building energy consumption', Renewable and Sustainable Energy Reviews, vol. $74, \quad$ pp. 902-924. https://doi.org/10.1016/j.rser.2017.02.085.

Dey, SR \& Tareque, M 2019, 'Electricity consumption and GDP nexus in Bangladesh: a time series investigation', Journal of Asian Business and Economic Studies, vol. 27, no. 1, pp. 35-48. https://doi.org/10.1108/JABES-04-20190029.

Electricity Consumption Per Capita of Uruguay 2017, retrieved from http://www.iea.org/data-andstatistics?country=URUGUAY\&fuel=Energy\%20consumpt ion\&indicator=Electricity\%20consumption\%20per\%capit a.

Electricity Consumption Per Capita of Panama 2017, retrieved from http://www.iea.org/data-andstatistics?country=PANAMA\&fuel=Energy\%20consumpti on\&indicator=Electricity\%20consumption\%20per\%capita

Electricity Consumption Per Capita of Chile 2018, retrieved from http://www.iea.org/data-andstatistics? country=CHILE\&fuel=Energy\%20consumption \&indicator=Electricity\%20consumption\%20per\%capita, 
Gooijer, JGD \& Hyndman, RJ 2006, '25 years of time series forecasting', International Journal of Forecasting', vol. 22, no. 3 , pp.

$443-473$.

https://doi.org/10.1016/j.ijforecast.2006.01.001.

Hussain, A, Rahman, M \& Memon, JA 2016, 'Forecasting electricity consumption in Pakistan: the way forward', Energy Policy, vol. 90, pp. 73-80. https://doi.org/10.1016/j.enpol.2015.11.028.

Islam, MS 2010, 'Electrical energy generation and demand forecasting of Bangladesh by econometric modelling' Master's Thesis, Bangladesh University of Engineering \& Technology,

Bangladesh. http://lib.buet.ac.bd:808o/xmlui/handle/123456789/362 5.

Islam, A, Hasib, SR \& Islam, MS 2013, 'Short term electricity demand forecasting for an isolated area using two different approaches', Journal of Power Technologies, vol. 93, no. 3, pp.

185-193.

https://papers.itc.pw.edu.pl/index.php/JPT/article/view/ 411.

Islam MR, Mamun, AA, Sohel, M, Hossain, ML \& Uddin, MM 2020, 'LSTM-based electrical load forecasting for Chattogram city of Bangladesh', 2020 International Conference on Emerging Smart Computing and Informatics (ESCI), Pune, India, 12-14 Mar, 2020, pp. 188192. https://doi.org/10.1109/ESCI48226.2020.9167536.

Jain, PK, Quamer, W \& Pamula, R 2018, 'Electricity consumption forecasting using time series analysis', in M. Singh, P. K. Gupta, V. Tyagi, J. Flusser, \& T. Ören (Eds), Communications in Computer and Information Science (pp. 327-335). Singapore: Springer. https://doi.org/10.1007/978-981-13-1813-9 33.

Jiang, W, Wu, X, Gong, Y, Yu, W \& Zhong, X 2020, 'HoltWinters smoothing enhanced by fruit fly optimization algorithm to forecast monthly electricity consumption',

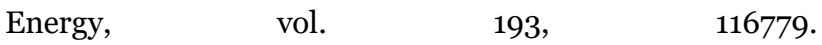
https://doi.org/10.1016/j.energy.2019.116779.

Key Energy Statistics of Bangladesh 2018, retrieved from http://www.iea.org/countries/Bangladesh.

Lepojevic, V \& Andelkovic-Pesic, M 2011, 'Forecasting electricity consumption by using holt-winters and seasonal regression models', Economics and Organization, vol. 8, no. 4 , pp.

421-431.

http://facta.junis.ni.ac.rs/eao/eao201104/eao201104o9.pdf.

Lee, YW, Tay, KG \& Choy, YY 2018, 'Forecasting electricity consumption using time series model (Special Issue 30)',
International Journal of Engineering \& Technology, vol. 7, no. $4, \quad$ pp. 218-223. https://doi.org/10.14419/ijet.v7i4.30.22124.

Maçairaa, PM, Souzab, RC \& Oliveira, FLC 2015, 'Modelling and forecasting the residential electricity consumption in Brazil with Pegels exponential smoothing techniques', Procedia Computer Science, vol. 55, pp. 328-335. https://doi.org/10.1016/j.procs.2015.07.057.

Medina, A, Cámara, Á \& Monrobel JR 2016, 'Measuring the socio-economic and environmental effects of energy efficiency investments for a more sustainable Spanish economy', Sustainability, vol. 8, no. 10, 1039. https://doi.org/10.3390/su8101039.

Mahmud, BN, Ferdoush, Z \& Mim, LT 2019, 'Modelling and forecasting energy demand of Bangladesh using AI based algorithms', Bachelor Thesis, Brac University, Bangladesh. http://dspace.bracu.ac.bd/xmlui/bitstream/handle/10361 $\not 12353 / 15301020, \% 2015301068, \% 2015301052$ CSE.pdf? isAllowed $=\mathrm{y} \&$ sequence $=1$.

Nawaz, S, Iqbal, N \& Anwar, S 2014, 'Modelling electricity demand using the STAR (Smooth Transition AutoRegressive) model in Pakistan', Energy, vol. 78, pp. 535542. https://doi.org/10.1016/j.energy.2014.10.040.

Nepal, B, Yamaha, M, Yokoe, A \& Yamaji, T 2020, 'Electricity load forecasting using clustering and ARIMA model for energy management in buildings', Japan Architectural Review, vol. 3, no. 1, pp. 62-76. https://doi.org/10.1002/2475-8876.12135.

Ostertagová, E \& Ostertag, O 2012, 'Forecasting using simple exponential smoothing method', Acta Electrotechnica et Informatica, vol. 12, no. 3 , pp. 62-66. https://doi.org/10.2478/v10198-012-0034-2.

Oliveira, EMD \& Oliveira, FLC 2018, 'Forecasting mid-long term electric energy consumption through bagging ARIMA and exponential smoothing methods', Energy, vol. 144, pp. 776-788. https://doi.org/10.1016/j.energy.2017.12.049.

Razak, FA, Shitan, M, Dan, AHH \& Abidin, IZ 2009, 'Load forecasting using time series models', Jurnal Kejuruteraan, vol. 21, no. 1, pp. 53-62. http://journalarticle.ukm.my/286/1/1.pdf.

Rahman, MZ, Sajib, MN, Rifat, MMSH, Hossam-E-Haider, M \& Khan, MAZ 2016, 'Forecasting the long term energy demand of Bangladesh using SPSS from 2011-2040', Proceedings of the $3^{\text {rd }}$ International Conference on Electrical Engineering and Information Communication Technology (ICEEICT), 22-24 Sep, 2016, Dhaka, 
Bangladesh,

pp.

https://doi.org/10.1109/CEEICT.2016.7873123.

Rahman, H, Selvarasan, I \& Begum AJ 2018, 'Short-term forecasting of total energy consumption for India- a black box-based approach', Energies, vol. 11, no. 12, 3442. https://doi.org/10.3390/en11123442.

Rajbhandari, Y, Marahatta, A, Ghimire, B, Shrestha, A, Gachhadar, A, Thapa, A, Chapagain, K \& Korba 2021, 'Impact study of temperature on the time series electricity demand of urban Nepal for short-term load forecasting', Applied System Innovation, vol. 4, no. 3, 43. https://doi.org/10.3390/asi4030069.

Stoimenova, E, Prodanova, K \& Prodanova, R 2007, 'Forecasting electricity demand by time series models', AIP Conference Proceedings, vol. 946, pp. 81-88. https://doi.org/10.1063/1.2806042.

Sustainable Development Goals of Bangladesh 2015, retrieved

from http://sdg.gov.bd/page/thirty_nine_plus_one_indicator/ 5\#1.

Sustainable Development Agenda in United Nations 2015, retrieved from http://www.un.org/sustainabledevelopment/development -agenda/.

Sarkar, MR, Rabbani, MG, Khan, AR \& Hossain, MM 2015, 'Electricity demand forecasting of Rajshahi city in Bangladesh using Fuzzy Linear Regression model', Proceedings of the $2^{\text {nd }}$ International Conference on Electrical Engineering and Information \& Communication Technology (ICEEICT), Dhaka, Bangladesh 21-23 May, 2015, pp. 1-3.

https://doi.org/10.1109/ICEEICT.2015.7307424.

Sisman, B 2016, 'A comparison of ARIMA and Grey models for electricity consumption demand forecasting: the case of Turkey', Kastamonu Üniversitesi İktisadi ve İdari Bilimler Fakültesi Dergisi, vol. 13, no. 3, pp. 234-245. https://dergipark.org.tr/tr/download/article-file/310001.

Sen, P, Roy, M \& Pal, P 2016, 'Application of ARIMA for forecasting energy consumption and GHG emission: a case study of an Indian pig iron manufacturing organization', Energy, vol. 116, pp. 1031-1038. https://doi.org/10.1016/j.energy.2016.10.068.

Shilpa, GN \& Sheshadri, GS 2017, 'Short-term load forecasting using ARIMA model for Karnataka state electrical load', International Journal of Engineering Research and Development, vol. 13, no. 7, pp. 75-79.
5. Sustainable Goals Tracker 2018, Ensure access to electricity for $100 \%$ population, retrieved from http://www.sdg.gov.bd/page/indicatorwise/5/441/3/o\#1.

Tepedino, C, Guarnaccia, C, Iliev, S, Popova, S \& Quartieri, J 2014, 'Time series analysis and forecast of the electricity consumption of local transportation', Proceedings of the $5^{\text {th }}$ International Conference on Development, Energy, Environment, Economics (DEEE '14), Firenze, Italy, 22-24 Nov, 2014, pp. 13-22. http://wseas.us/elibrary/conferences/2014/Florence/DEEE/DEEE-01.pdf. Tirkeş, G, Güray, C \& Çelebi, N 2017, 'Demand forecasting: a comparison between the holt-winters, trend analysis and decomposition modfels', Tehnički vjesnik, vol. 24 (Suppl. 2), pp. 503-509. https://doi.org/10.17559/TV20160615204011.

Towards Data Science 2019, The complete guide to time series analysis and forecasting, retrieved from https://towardsdatascience.com/the-complete-guide-totime-series-analysis-and-forecasting-70d476bfe 775 .

Wang, CH, Grozev, G \& Seo, S 2012, 'Decomposition and statistical analysis for regional electricity demand forecasting', Energy, vol. 41, no. 1, pp. 313-325. https://doi.org/10.1016/j.energy.2012.03.011.

World Bank Data 2018, Annual GDP growth of Bangladesh, retrieved from http://data.worldbank.org/indicator/NY.GDP.MKTP.KD. ZG?locations $=B D$.

World Energy Outlook 2018, International Energy Agency publications: Paris, France, 2018, retrieved from https://www.iea.org/reports/world-energy-outlook-2018.

Zahan, M \& Kenett, RS 2013, 'Modeling and forecasting energy consumption in the manufacturing industry in South Asia', International Journal of Energy Economics and Policy, vol. 3, no. 1, pp. 87-98. https://media.proquest.com/media/pq/classic/doc/28574 86521/fmt/pi/rep/NONE?_s=rQtqomueIk6El6jJxxBmud $\underline{\mathrm{mNtcs}} \% 3 \mathrm{D}$.

\section{NOMENCLATURE}

$F_{t} \quad$ Forecast at time period $t$

$M A \quad$ Moving average

$A_{i} \quad$ Actual consumption in time period $i$

Number of periods (data points) in moving average

$i \quad$ The index corresponds to periods 
$F_{t-1} \quad$ Forecast of the previous period

$\alpha \quad$ Smoothing constant $(0<\alpha<1)$

$A_{t-1} \quad$ Actual value of the previous period

$F_{t+h} \quad$ Forecast for period $h$

$l_{t} \quad$ Estimated time of level at time period $t$

$h \quad$ Forecast period

$b_{t} \quad$ Estimated time of trend at time period $t$

$L_{t-1} \quad$ Previously estimated time of level

$T_{t-1} \quad$ Previously estimated time of trend

$S_{t-p} \quad$ Previously estimated time of seasonal

$T_{t} \quad$ Long-term trend

Ct Cycle

$S_{t}$

Expressed in terms of trend $T_{t}$ in the Multiplicative model

$l_{t}$

Expressed in terms of cycle $C_{t}$ in the

Multiplicative model

$S_{t} \quad$ Seasonality in the Additive model

$l_{t} \quad$ Irregularity in the Additive model

$\beta_{o} \quad$ Trend line intercept

$\beta_{1} \quad$ The slope of the trend line

$\beta_{2} \quad$ Rate of change in slope

$t \quad$ Time period 